\title{
EXAMINING THE ORIGIN OF FLOWERPOT MOTIFS IN THE BUILDINGS OF QAJAR ERA
}

\author{
T. Benisi ${ }^{1}$, F. Zarezadeh ${ }^{2}, *$ \\ ${ }^{1}$ Faculty of Art \& Architecture, Tarbiat Modares University, Tehran, Islamic Republic of Iran - benisi_t@yahoo.com \\ ${ }^{2}$ Faculty of Art \& Architecture, Tarbiat Modares University, Tehran, Islamic Republic of Iran - f.zarezadeh@ modares.ac.ir
}

KEY WORDS: flower pot motives, Qajar, architecture, decorative elements, spiral floral motives

\begin{abstract}
:
In Qajar period, the era of the formation of urban fabric along with a rooted tradition close to the contemporary architectural era of Iran, specific motifs and decorative patterns were formed on the buildings, including flowerpots with scattered flowers that developed on all constructions of this era (the mosques, schools, palaces, and mansions), which were applied with assorted materials especially seven-color tiles.

The present study was a descriptive-analytic research conducted referring to reliable library resources, and visual and electronic documents, and, it was intended to answer the following question: What is the origin of scattered flowers with spiral stalks issuing from realistic and abstract flowerpots?

Findings show that the origin of scattered flowers with symbolic meanings of life, growth and immortality is the earthenware found in Sialk, Kashan, which were common in ancient era and after Islam, they became widespread with the same content and theme as arabesque forms. Then, they were recreated in Qajar Era and by being originated from realistic and sometimes abstract flowerpots, they were depicted on the buildings with symmetric spiral arabesque forms.
\end{abstract}

\section{INTRODUCTION}

Ornaments and decorative elements are complementary to the architecture of each era, and they originate from its culture and mindset. Over the course of time, these ornaments create certain styles. Motifs applied in deep-rooted, age-old civilizations do not emerge overnight and are never disaffiliated from the past. In other words, it can be claimed that they are the outcomes of coalescence between old motifs and contemporary thoughts. As the most recent historical period before the contemporary era, Qajar reign witnessed the emergence of particular conditions, namely the formation of modern urban texture, which preserved the old traditions as well. During this stretch of history, flower pot motifs and spiral floral patterns became the staple decorative elements of architectural features. However, the question regarding the origins of such motifs remains unanswered; How old are they and which motifs' developments resulted in their creation? Drawing upon a descriptive-analytical viewpoint, the present study uses images from earlier periods to examine the origins of the aforesaid floral Title of the paper

Full papers submitted for double-blind review to the Annals must not contain any information which makes it possible to identify the authors. In particular, names and affiliations must be removed from the manuscript submitted for review. Also sentences such as "As we have shown in previous work (Author_x, 20xx)" are to be avoided. Instead use a formulation such as "Author_x (20xx) has shown ...". Note that submissions which have not been appropriately anonymised may be subject to immediate rejection.

\section{THE ORIGIN OF SPIRAL FLORAL MOTIFS USED IN THE BUILDINGS FROM THE ISLAMIC PERIOD IN IRAN}

floral elements never faced jurisprudential bans, and have been a staple part of decoration in all post-Islamic structures. While such elements carry the attributive meanings of their own, they also denote more otherworldly connotations such as the eternal afterlife and the divine paradise. The paradise has been described as a quadrilateral garden (charbagh) in Quran. The four gardens are mystically represented as four stages through which, the disciple (Salek) takes an inner journey. These four gardens/ stages are the garden of self, the garden of heart, the garden of soul, and the garden of essence. For mystics, the garden of paradise is where one can commence their spiritual ascend. Nasr, 2010

This section examines the origins of spiral floral elements and their emergence in various eras of Islamic- Iranian architecture.

\subsection{Flower pot motifs from the Qajar reign: the origin of} spiral floral elements

Flower pot arrays are abundant in all architectural creations of the era. The pot or vase is placed as a symmetrical centerpiece in a frame (most common on walls), and it may be realistic or abstract. Floral elements flow outwards to cover the frame. Such an ornament was not exclusive to a certain category of buildings.

Rather, it was profusely used in mosques, schools, palaces, mansions, and other buildings (figures 1, 2, 3, 4).

\footnotetext{
* Corresponding author
} 


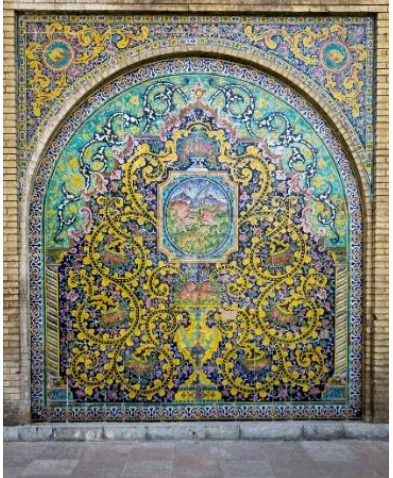

Figure 1. flower pot pattern, Golestan Palace walls, Tehran, author, 2019

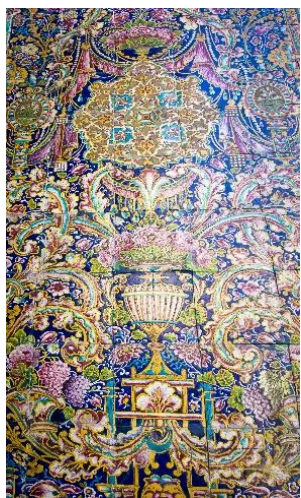

Figure 2. realistic flower pot motif, beside the entrance of Sepahsalar Mosque, Tehran, author, 2019

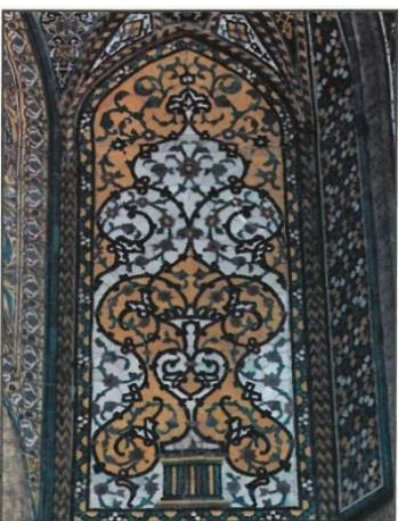

Figure 3. Sepahsalar Mosque, Tehran, Dibaj, 2009

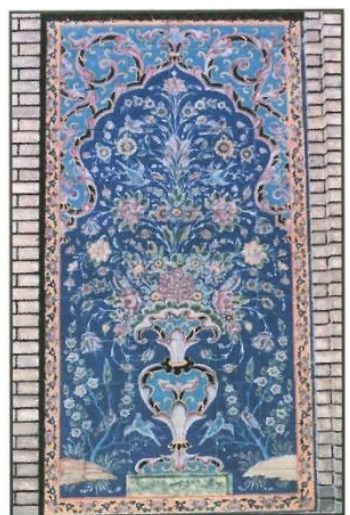

Figure 4. Sepahsalar Mosque, Tehran, Dibaj, 2009
As it is evident in the images, sometimes the pot is simply formed symmetrically from an arabesque motif, and other times it is realistically drawn. During the rule of Qajars, the pots tended to seem more realistic because of the developments of the time and the influence of occidental art on the social structure of Iran.

The pot symbolizes a goblet that receives divine effects. The goblet contains several types of flowers and can reflect the virtues and symbols of various flowers all in one place (Shovalieh, Vol. 1). Spiral motifs can also be spotted on the facades. Here, they initially emerge as medallion among other motifs. However, the flower pot is more commonly used on the main walls.

2.2 The origin of spiral floral elements in the structures from the Zand and Afshaird dynasties $\left(1^{\text {th }}\right.$ century)

During the rule of Zand Dynasty, flower pot motifs did not appear in buildings as often as Qajar. On the main walls, they are mainly replaced by more realistic arrays of floral motifs and birds (gol-o morgh). The use of flower pot is mainly restricted to smaller spaces, such as the space between the pairs of muqarnas or the area separating two window frames. Floral elements mostly originate from the lower horizontal side of the frame (representing the ground/Earth). Trees and other elements cover the whole area inside the frame right to the top, and there are flowers and birds ornamenting on the trees (figures 5, 6).

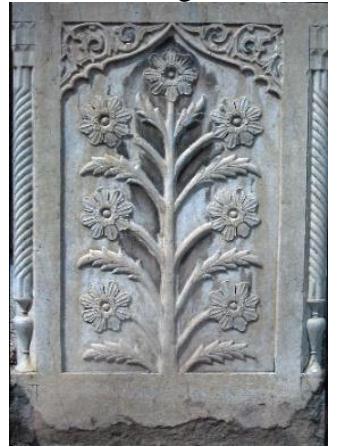

Figure 5. A bas-relief of a flower growing from the lower side of the frame, Vakil Mosque, Shiraz, Sarvestani, 2005

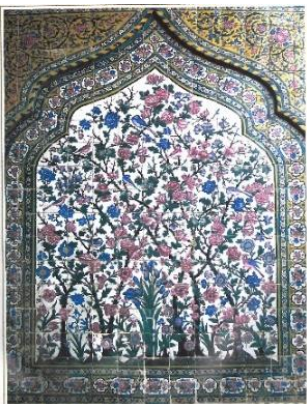

Figure 6. Flower and bird motifs originating from the lower side of the frame, Vakil Mosque, Shiraz, Sarvestani

\subsection{The origin of spiral floral motifs in the buildings from the Safavid Dynasty $\left(16^{\text {th }}\right.$ century)}

Abstract Islamic motifs in general and arabesques and palmettes in particular met their zenith under the Safavids' rule. It is the conception of the conscience and truth, that leads the artists to choose such expressions of forms and colors. The religiousIslamic-Iranian arts bare the objects and forms from their 
mundane figures and shape them up using divine forms and concepts. Objects are rooted to their divine essence, so they reflect the eternal [divine] grace and glory (Dibaj, 2009).

In this era, these elements are often placed in the center of the pattern or the lower $1 / 3$ of the cadre (in symmetrical arrangements). Palmettes and scrolls beautifully cover the area with tendrils and foliage proportionately adorn the spiraling stems (figure 7).

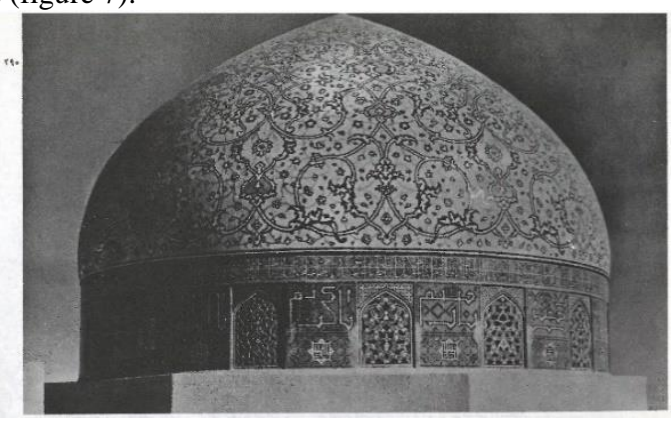

Figure 7. Sheikh Lotfollah Mosque, A. Pope, 1994

As can be seen in the images, the flower pot motif emerges out of intertwining tendrils and arabesques, resulting in the formation of pot forms. Later, it is modified and developed. Flower pot motifs of the era are stylized in an abstract way (Figure 8). The exquisite ornaments of the epoch and the alluring turns of tendrils and spirals whose origins and ends are faded and hidden under the main motifs, all depict the plurality that moves towards unity.

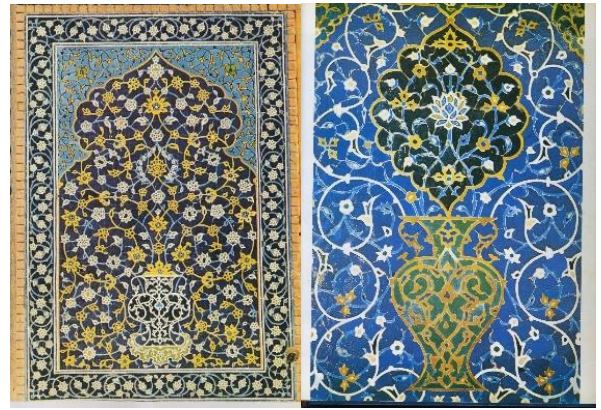

Figure 8- spiral flower pot motif, Charbagh School, Shah Sultan

\subsection{The origin of floral motifs in the structures built between $12^{\text {th }}$ to $15^{\text {th }}$ centuries}

When studying the works of this period, the Blue Mosque of Tabriz stands out. Known as the Islamic Turquoise, it dates back to 1465 (A. Pope, 1994). The brilliant white scripts are laid on a background of elaborately decorated mosaic tiles with foliate patterns. Some parts of the façade are decorated with reliefs with a medallion of Kufic style (A. Pope, 1994), which functions as the centerpiece from which the tendrils and scrolls originate.

The flower pot motif does not visibly stand out in these patterns; Still, the visuals clearly bring to mind a motif of such a nature. In the coming centuries, the same motifs develop into a pattern more obviously similar to a flower pot (figure 9). No trace of flower pot motifs was found in the books and websites on the Blue Mosque

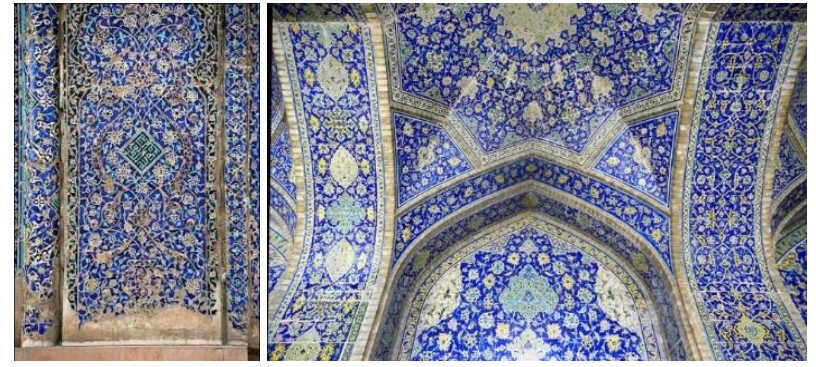

figure 9. Blue Mosque, Tabriz, Tehran Times, 2016

Another exquisite structure of the era is the Pir Bakran Mausoleum in Isfahan. Built under the Ilkhans' rule, its mihrab is decorated with floral and foliage patterns, tendrils, and Kufic and Thulth scripts. The spiral patterns originate from intercrossing lines, which form a medallion-like motif in the center [the decoration of this structure does not include much details, Pope, 1994] (Figure 10).

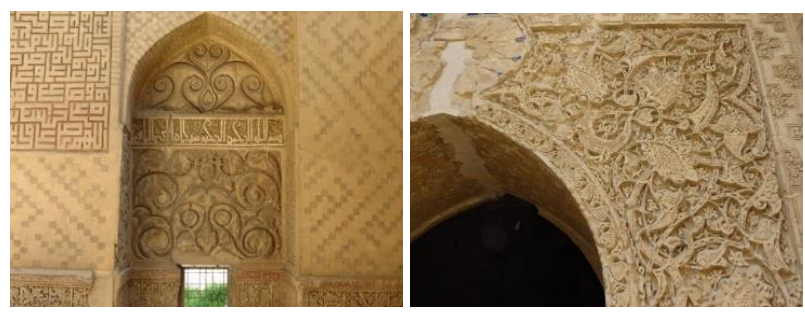

Figure 10. Pir Bakran Mausoleum, Imna, 2013

Another Ilkhanid monument is the mosque of Heydariyeh School in Qazvin. Here, the spirals originate from the lower horizontal side of the frame. This structure is also empty of finely detailed motifs.

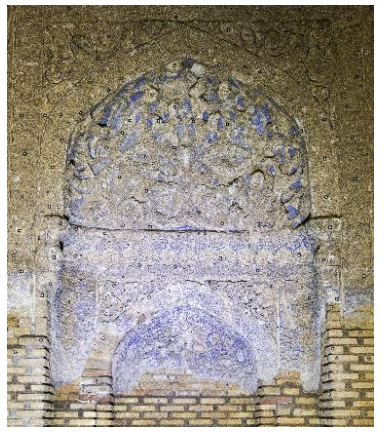

Figure 11. the mosque of Heydariyeh School, author, 2018

\subsection{The origin of spiral floral motifs in Iran, from the $10^{\text {th }}$ or $12^{\text {th }}$ century}

Brickworks are the most dominant decorative elements of the buildings in this era. The motifs have an increasing tendency towards becoming more geometrical. Scripts are abundant and exquisite, and yet they do not overshadow the demonstration of floral ornamentations. The foliage and floral patterns cross through the scripts and yet, do not intertwine with them. In other words, the motifs are either based on the letters of the scripts, or not laid over them (Andre Godard, 1993) (figure 12). 


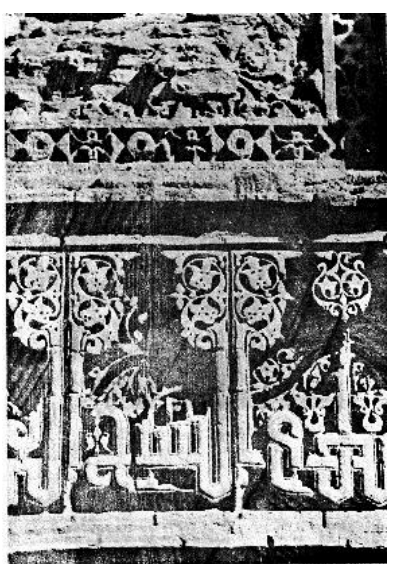

Figure 12. Khargerd, Part of a Script of School, Seljuk Period, Andre Godard, 1993

Yet another structure whose spirals and tendrils are worthy of consideration is Robat-e Sharaf Caravanserai on the MarvNishapur road (Andre Godard, 1992, 176). Stucco spirals and tendrils can be seen on the inner surface of the entrance (figure 13). As seen in the image, motifs originate from a center of symmetry in the lower part of the pattern, and move upwards from there. Repetition of these patterns has formed medallions.

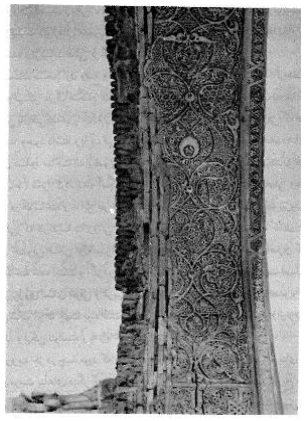

Figure 13- Robat-e Sharaf, Andre Godard, 1992

2.6 The origin of plant motifs in Iranian monuments from the beginning of Islam to the $4^{\text {th }}$ century

The achievement of Islamic Iran was that it refined the basic elements of the culture and civilization of the past and raised their ability (A., Pope, 1994). The ancient Islamic monuments in their current simple form were likely to look imperfect and uniform in the eyes of their architects, because the architecture of that era was associated with too many decorative and nested artworks. They included colorful stuccos perfectly designed and used in the monuments. One of the oldest mosques built in this period is the Jāmeh Mosque of Nā'în, dating back to the middle of the tenth century AD. (A., Pope, 1994).

On the altar of this mosque are plant and spiral motifs starting from the horizontal lines of the bottom of the cadre. Professor Pope believes that the building of this monument dates back to $851 \mathrm{AH}$, while André Godard attributes it to the Daylamites (Art Online, 2014).

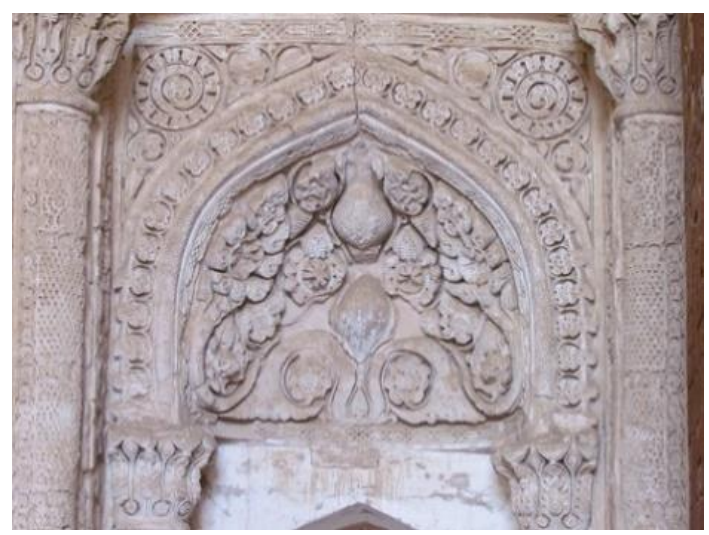

Figure 14. Part of the altar of the Jāmeh Mosque of Nā'īn, Iran Trip Yar

Most of the monuments of this period are characterized by brickwork, decorated with geometric motifs, but few plant motifs.

\section{THE ORIGIN OF PLANT MOTIFS IN THE PRE- ISLAMIC MONUMENTS OF IRAN}

The first monuments of Iran date back to the Neolithic period (5800-6200 BC). For example, the remnants of large houses (made of hand-made clay) are seen in Ali Kosh Tell. One of the most interesting monuments identified there was "the mountainous land" In Sialk. From the $5^{\text {th }}$ millennia BC, the oldest places of living there relating to the early part of the $5^{\text {th }}$ millennium appeared to be huts made of branches of trees. Although the inhabitants were engaged in primary gardening and domesticating cattle and sheep, they had hand-made pottery as well. At the next stage, the arrangement of primary architecture was introduced and the walls of the rooms were painted with patina mixed with fruit juice. Flat square-shaped sun-dried bricks, which were molded and used in the fourth millennium, seemed to be an Iranian invention (A., Pope, 1994:15).

We will deal with the decorative plant motifs on the monuments and their origins in pre-Islamic periods in the following section.

\subsection{The origins of plant motifs in Sassanid monuments}

While the Sassanids continued to evolve the important Parthian shapes and added valuable achievements to it, they supported the continuation of the old shapes of Iran, especially what was related to the magnificence of the Achaemenid (A., Pope, 1994). The Iranian spirit returned to creative arts in the Sassanid period. Thus, the remaining motifs of the monuments reflect the Iranian identity and its roots. 


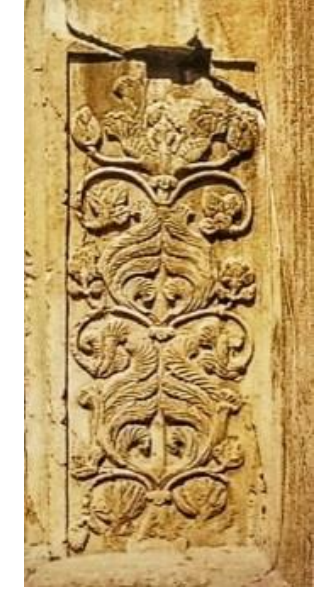

Figure 15. Taq-e Bostan, Giovanni Curatola, John Roberto, Gianroberto Scarcia, 2015

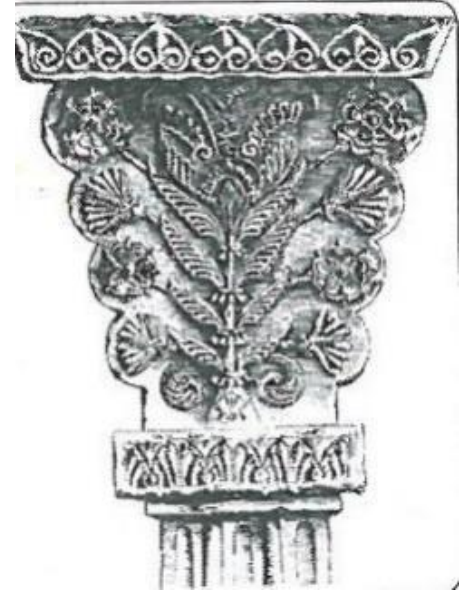

Figure 16 - Part of the column of Taq-e Bostan, Majid Azadbakht, 2018

The "Tree of Life" is one of the carved plant motifs in Taq-e Bostan. A look at this image shows that:

1. The origin and growth place of the tree is the ground (horizontal lines in the bottom of the cadre).

2. Its rotating branches are scattered across the entire cadre and have moved upward (symmetrically).

3. There is a similarity between this motif and the plant and Slavic motifs in post-Islamic periods (a source and origin For plant motifs).

4. This motif has ended in a bud, showing the continuation of growth and life.

5. The shapes in the middle of it are reminiscent of bergamotshaped motifs in vase designs and signs.

Image 16 shows a part of Taq-e Bostan, resembling the columns of the Vakil Mosque in its general form (branches symmetrically separated from the midline and horizontal growth place (see figure 7).

\section{2 the origin of plant motifs in the monuments of the Parthian and Seleucid periods}

The Parthians uniquely combined the Greek and Persian elements and contributed a lot to the growth of architecture (A., Pope, 1994) (in access to squinch dome and the formation of the arched ivan (vault). One of the monuments of the Parthians in Iran is Robat Sefid with no special decorations. The monuments may have had no decorations from the beginning, or their decorations may have disappeared after so many years.
Most of the monuments that can be studied are located outside of present-day Iran, such as Hatra Palace in present-day Iraq (in the southwest of Mosul). There is a relief of winged lions by a vase of lily flowers at the entrance to the Hatra Palace, which is related to the Seleucid period (figure 17).

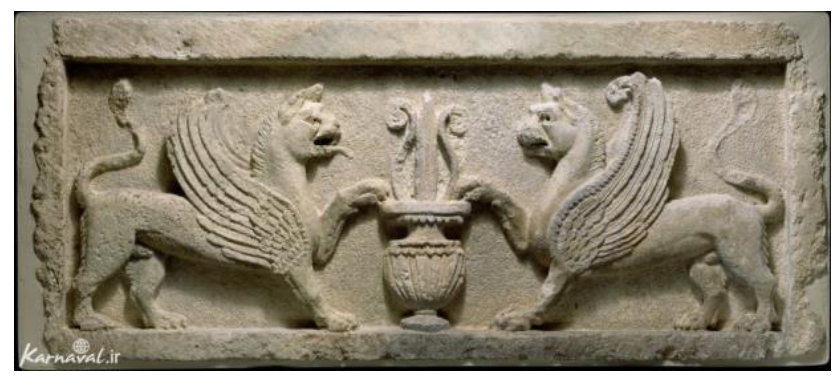

Figure 17. The relief of lions and a vase of lily flowers, Azadbakht, 2018

During the reign of Alexander's succeeders (the Seleucids), the Iranian design tradition was temporarily influenced by Greek imports and the features of the Greek design elements were used in Iranian decorations (A., Pope, 1995).

The remnants of the Khurheh Temple, relating to the Seljuk period, and the narrow columns as high as stone capitals belong to the Seleucid- Parthian period and were built in the Ionic order, which was the outcome of ancient Greek art (ISNA, 2014).

Rome contributed to Iran's sculptural thoughts and techniques, and Hellenistic features spread in Iran during the centuries after Alexander's invasion of Iran, but none of these Western influences had a profound effect on people's habits. The absorption of these different themes and styles was complicated and often vague, but regardless of their origin, they were finally absorbed in the treasure of Iranian art and turned out to be Iranian in terms of nature and application (A., Pope, 1995).

\subsection{Plant motifs the Achaemenid era}

The first world empire began in Iran as early as $561 \mathrm{AD},(22)$, and lasted for 281 years (A., Pope, 1994: 22). Plant motifs were abundant in this period, for example, the lines of soldiers in the reliefs intersect at a common point, and their symmetry is separated only by the representation of the tree of life. The groups are regularly displayed with pine trees or by a change of characters and garments. The vertical ornamental reliefs indicate sustained support (A., Pope, 1994). The legs of the columns are like water lily flowers, which symbolize perfection and vivific power. The capitals of Apadana Ivan (vault) display palm trees with hanging leaves, while the growing tendrils at the other side represent flourishing.

Among the reliefs which have remained from this period is the relief of a tall plant, whose leaves are lying on, branching from and sitting on one another, and ending in a half- flower. Some say it is a palm, some others think it is a lily flower, and some other say it is an iris flower (figure 18). What is important is that this plant has had sanctity. Another relief shows this plant with a winged lion having a human head with his hand on the flower (perhaps as a sign of care (figure 19). What is important in this study is the form and design of the plant, its branching from the ground (its origin) and its rhythmic upward growth used later. 


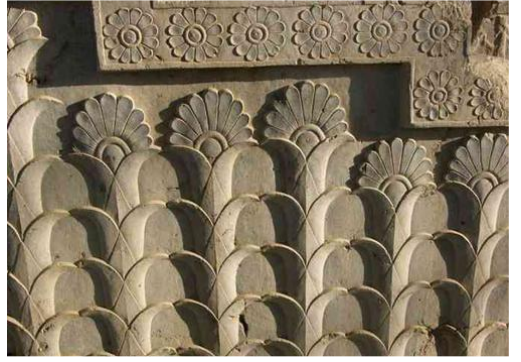

Figure 18. A motif of the sacred plant, Persepolis, wisgoon.com, 2005

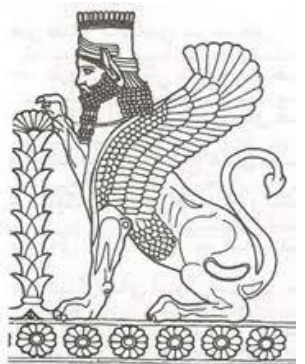

Figure 19. The motif of a lion with a flower, Rasekhoon, 2013

Another plant symbol seen in this period is the symbol of a cypress tree cared for by a guardian or guardians. It was called the Tree of Life in the Achaemenid period (Image 20).

As seen in the image, the tree branches have come out of the main branch and are moving upright. Circular movements are also seen on the branches and the end of the main stem has three branches.

Somewhere else, there is a relief of an Achaemenid man with a cup in his hand looking like the vases of the Contemporary period (and the Qajar period) with signs of animals on the vase hand. The vase was used for drinking (Image 21).

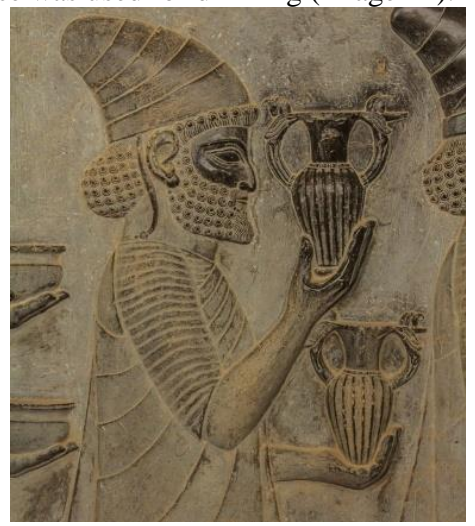

Figure 21. The relief of an Achaemenid man with a cup in his hand, Epochlimes, 2016

\section{THE ORGIN OF PLANT MOTIFS IN PREHISTORIC MONUMENTS}

\subsection{Plant motifs in the Monuments of the Medes and Elamites}

Massive buildings with stone columns were constructed in the architecture of the Medes. They had a simple architecture, but can be considered the foundation of Iranian architecture due to ther specific features (Parstoday, 2016). Cyaxares (the king of Media) selected Ekbatan or Hegmataneh, the present-day
Hamedan, as his capital in the late seventeenth century (A., Pope, 1994). The catacombs remaining from them can provide information about the plant motifs of this period. One of these catacombs in Qizqapan in present-day Iraq shows columns in the Ionic order with a flower motif in the middle (figure 22).

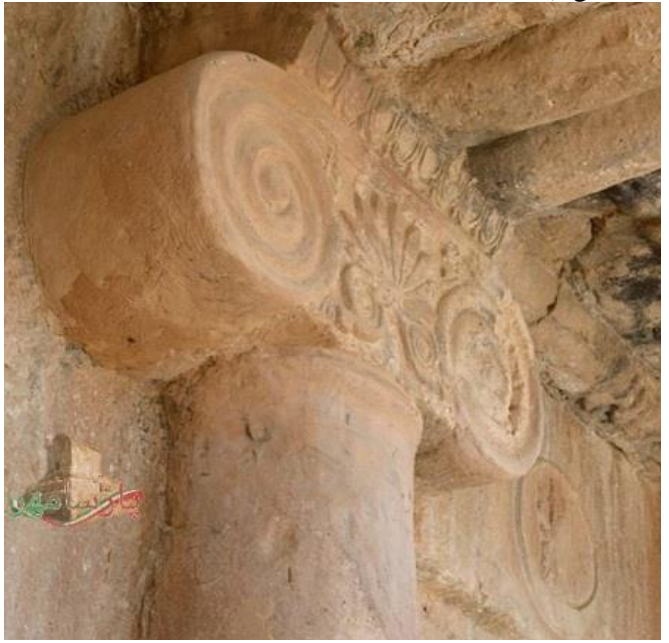

Figure 22. A close-up of Qizqapan capital

The Elamites, who were the first inhabitants of a region of Iran, present-day Khuzestan, and whose first government was formed in the third millennium, created a circle between Iran and Sumer (A., Pope, 1994). The most important monument of the Elamites is Chogha Zanbil Ziggurat, which is the oldest known historical monument in Iran with an impressive nature and dimensions and covered in many places with furnace glazed bricks in blue, green and shiny colors. Its building has been decorated with ivory (A., Pope, 1994).

The best reference for studying this period's motifs can be the pottery pieces discovered in Susa and Haft Tape, whose designs reveals the growth of the Elamites' abstract thinking. For example, on the Susa Cup, kept at the Louvre Museum, a plant has been surrounded by goat horns symbolizing the moon, and the goat itself symbolizes the vegetation. The goat in Susa was a symbol of prosperity and the god of plant life (Azadbakht, 2018, figure 23). The plant has grown from the right of the enclosed circle and seven branches have continued on a regular basis. Its vertical form reminds us of the simple motifs of the Achaemenid period.

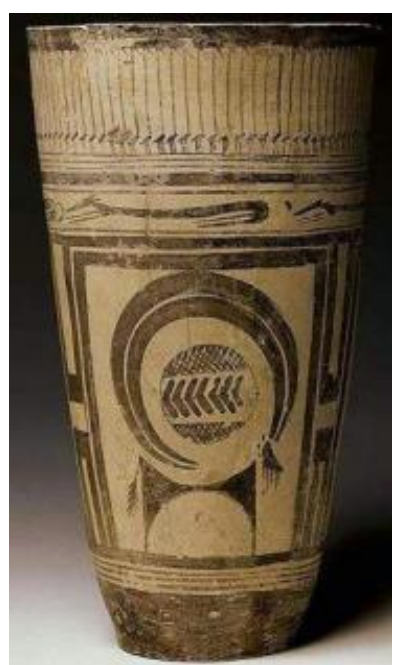

Figure 23. Susa Cup, Parsiyannet 


\section{PLANT MOTIFS OF SIALK AND THEIR ORIGINS}

Roman Ghirshman described Sialk as the oldest human settlement on the central Iranian plateau, and attributed its first remnant to the fifth millennium BC. Rafiei $(1998,370)$ divided it into three stages. The third period of Sailk (Sialk III) is a new stage in the evolution of prehistoric civilization of Iran and is related to the major part of the fourth millennium BC (Rafiei, 1998: 104). A new material came to be used in the architecture of this time and elliptical sun-dried bricks ceased to be used and were replaced by smooth and rectangular sun-dried bricks made of soft soil (Ghirshman, 1991: 20). There were pieces of pottery in this period with a lot of geometric motifs as well as abstract plant and animal motifs.

The plant symbol, which grows horizontally and moves upwards, has been displayed by curved and spiral lines (figures 34,35 and 36), which can be considered the primary form of the spiral motifs that were used later to decorate the artworks. Some have been regarded as the plant symbol related to the moon (Abdollahian, 1999, Honar Name, Issue 2, 54). These curved lines have come from one another and associate the form of a tree in ones mind, which is probably the reason why some have called it the "tree of life" (Hoama). This symbol is bigger than the animal and bird motifs on the pottery pieces and has taken a different independent form.

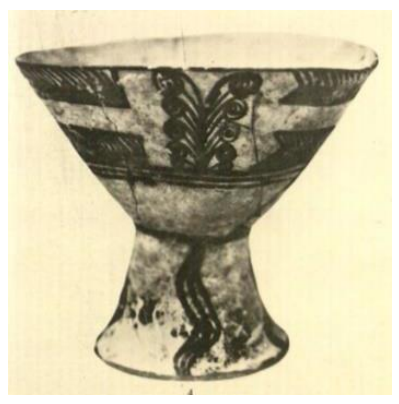

Figure 24- A legged small cup with the plant symbol, Ghirshman, 1938, 9 N, 91

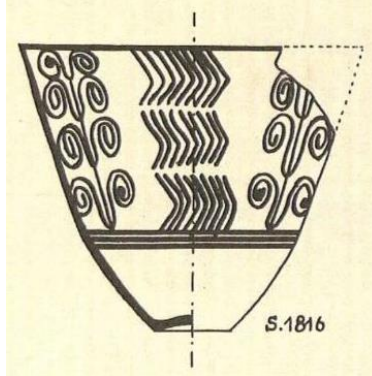

Figure 25- Ghishman, 1938

According to the author's field research and visit to Tape Sialk, this motif was seen even in the Silak II period, which dates back to before the fifth millennium (figure 26).

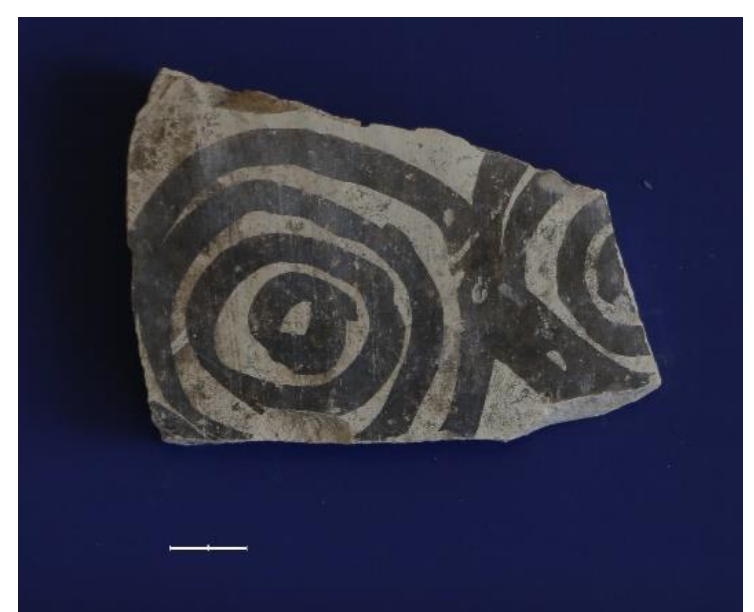

Figure 26- A broken piece of pottery with the plant symbol, Sialk II, author, 2018

\section{CONCLUSION}

Evidence from the history of Iran suggest the sanctity of plants and their connection with the continuity of life in people's culture and thoughts, and they are used as valuable creatures on adornments of the buildings such that they are clearly protected in the motifs of buildings. Sialk pottery, which is regarded as the origin of motifs shows their rotary movement as an evolutionary process into becoming a spiral form. These motifs originate from the ground (the horizon) and are drawn to a size larger than other designs on the pottery. Relatively symmetric motifs originate from the center of the previous motif that associate birth and life. Rhythm, harmony, continuity, and moving upward have accompanied the spiral motifs since the beginning (in Sialk motifs).

Spiral motifs gained their general form before Islam like the Tree of Life motif in Taq-e Bostan (Sasanid era) on which leaves and buds are mounted (Figure 24). (Even a baluster motif is seen among them, which are grown from inside the previous motif as seen in Sialk plant motifs (Figure 25) and later, some motifs similar in form are found in Vakil Mosque in Islamic era). After Islam, the spiral motifs adorned the buildings via arabesque and khatai motifs, and they became the basic adornment for buildings. Since early Islamic era in Iran, they adorned buildings with mystical connotations. First, they originated from horizontal or sometimes vertical lines and then, they developed from the signs and medallions.

Since 10th century, flowerpot motif was used as an abstract phenomenon with spiral and curved stalks, and, scattered spiral motifs with flowers and leaves adorn buildings beautifully. Then, we see them in three forms in the buildings, i.e. scattered spiral plants flowing out of flowerpots, motifs originated from signs and medallions, and motifs originated from the ground (mostly found in Zand era). In later eras, realistic flower, leaf and flowerpot motifs are seen which are very close to paintings. With changes occurred in Qajar era and their effect on today's world, (more connection with the west and formation of the urban texture as seen today), realistic motifs originated from previous eras are developed in this era and flowers and flowerpots are seen more realistically. Flowerpots (with their mystical content) with scattered motifs adorn all sorts of buildings (flowerpot motif is also found in pre-Islamic eras, Figures 25 and 30) such that all historic buildings of this era are adorned with flowerpot motifs. Qajar flowerpot motifs are implemented in holy buildings as well as palaces and homes. 
With their realistic form, they approach the modern art, and, with their abstract form, they embrace the Islamic spirit of mystical art.

\section{REFERENCES}

Abdollahian, Behnaz (1999), symbolic concepts of stamp and moon in prehistoric pottery, Honarnameh (Bulletin of Art), No. 2, Tehran: Ministry of Culture and Islamic Guidance, 46-63

Azadbakht, Majid (2018), Teaching General Perception of Art I, History of Iranian Art, Tehran: Kolk Moallem Sajedi

Ghirshman, R (1933, 1934. 1937) Foulles de sialk presde Kashan v.1 France

Ghirshman, Roman (2000), Kashan Silk 1, Asghar Karimi, Tehran: Cultural Heritage Org.

Godar, Andre (1992), Effects of Iran (1-2), Abolhassan Sarv Moghadam, Mshhad: Astan Ghods Razavi

Mirshamsi, Fereshteh Sadat (2017), variety of plant motifs on mural of Zandieh Era in Shiraz, Fine Arts- Visual Arts, round 22, No. 1: 44-52

Nasr, Seyed Hossein (1996), Islamic Art and Intellectuality, Rahim Ghasemian, Tehran: Hekmat

Pop, A (1994), Architecture of Iran, Gholamhossein Sadr Afshari, Tehran: Farhangian.

Rafiei, Leila (1998), Iranian ceramic from prehistoric times up to the present, Tehran: Yasaveli Majallat

Shovalieh, Jane, Griran, Allen (2000), Symbols Culture, volume 1, Soudabeh Fazeli, Tehran: Jeihoun 